\title{
Comparative Study on Interface Elements, Thin-Layer Elements, and Contact Analysis Methods in the Analysis of High Concrete-Faced Rockfill Dams
}

\author{
Xiao-xiang Qian, Hui-na Yuan, Quan-ming Li, and Bing-yin Zhang \\ State Key Laboratory of Hydroscience and Engineering, Department of Hydraulic Engineering, Tsinghua University, \\ Beijing 100084, China \\ Correspondence should be addressed to Bing-yin Zhang; byzhang@tsinghua.edu.cn
}

Received 3 June 2013; Accepted 15 August 2013

Academic Editor: Pengcheng Fu

Copyright (C) 2013 Xiao-xiang Qian et al. This is an open access article distributed under the Creative Commons Attribution License, which permits unrestricted use, distribution, and reproduction in any medium, provided the original work is properly cited.

\begin{abstract}
This paper presents a study on the numerical performance of three contact simulation methods, namely, the interface element, thin-layer element, and contact analysis methods, through the analysis of the contact behavior between the concrete face slab and the dam body of a high concrete-faced rockfill dam named Tianshengqiao-I in China. To investigate the accuracy and limitations of each method, the simulation results are compared in terms of the dam deformation, contact stress along the interface, stresses in the concrete face slab, and separation of the concrete face slab from the cushion layer. In particular, the predicted dam deformation and slab separation are compared with the in-situ observation data to classify these methods according to their agreement with the in-situ observations. It is revealed that the interface element and thin-layer element methods have their limitations in predicting contact stress, slab separation, and stresses in the concrete face slab if a large slip occurs. The contact analysis method seems to be the best choice whether the separation is finite or not.
\end{abstract}

\section{Introduction}

The cracking of the concrete slab is the most important factor affecting the safety of concrete-faced rockfill dams (CFRDs). Accurate computation of stress and deformation in the concrete slab are key issues for slab cracking assessment. Numerical methods can be used to predict the deformation and stress distributions in the concrete face slab, where the behavior of the interface between the concrete face slab and the cushion layer plays a significant role. Because the interface can be treated in different ways, the prediction of displacement and stress distribution around the interface may be different. This study focuses on the comparison of different interface analysis methods through the analysis of stress and displacement distributions near the interface in the Tianshengqiao-I CFRD project. The accuracy and limitations of each method are discussed.

Much attention has been paid to numerical treatment of the interfaces in geotechnical problems such as buried structures, jointed rocks, and rockfill dams [1-5]. Interface behavior often involves large relative movement or even debonding [6]. Over the past three decades, three numerical methods have been proposed for simulating the displacement jump along the interface: the interface element, thinlayer element, and contact analysis methods. The interface element method originated from the Goodman joint element approach [2-6]. The basic idea was to introduce a constitutive model for an interface of zero thickness [6]. This constitutive model may be elastic, rigid-plastic, or elastic-plastic $[2,6,7]$. As an alternative, a thin-layer element method [8] was proposed. The thin-layer element method regards joints or interfaces as conventional continuums described by solid elements. However, the material modulus for this thin layer is much lower than that for the intact solid [811]. This thin-layer element method has been successfully applied to jointed rock masses [10], buried pipes [8], and the interaction of foundation and soil masses $[9,11]$. Either the interface element or thin-layer element is limited to small deformation. Different from the previous two numerical methods, the contact analysis method was proposed to simulate the contact behaviors between the concrete face 
slab and the cushion layer in the Tianshengqiao-I concretefaced rockfill dam [12]. In this contact analysis method, the concrete face slab and dam body were regarded as two independent deformable bodies, and the contact interface was treated using contact mechanics [13]. This method allows large relative displacements between the concrete face slab and cushion layer. The physical and mechanical properties of the interface can also be nonlinear or elastic-plastic. In the contact analysis method, the detection of the contact is the key issue. Zhang et al. [12] proposed a local contact detection method at the element level, where the search is localized between two elements and thus needs less time. However, the accuracy of this contact detection method is not acceptable when the mapping function for element geometry is not identical to that for displacement interpolation and when the deformation is large. In this paper, a global contact search method is proposed based on a radial point interpolation method $[14,15]$. The accuracy of this global search method is controllable.

In this study, the numerical performance of three numerical simulation methods, namely, the interface element, thinlayer element, and contact analysis methods is compared through stress-deformation analysis of a high concrete-faced rockfill dam. In Section 2, the fundamentals of the three methods are briefly reviewed. A global search method for contact detection is proposed based on the radial point interpolation method. In Section 3, the constitutive models for the rockfill dam body and the concrete face slab are presented. The Duncan EB model [16] is employed to describe the nonlinearity of rockfill materials, and a linear elastic model is used to describe the mechanical properties of the concrete face slab. In Section 4, the FEM models and material parameters are introduced. Section 5 compares the performance of the three numerical methods using the Tianshengqiao-I CFRD project in China as an example. The separation between the concrete face slab and the cushion layer, stresses in the concrete face slab, contact stress along the interface, displacements along the interface, and deformation of the dam body are compared using the in-situ observations available. Finally, conclusions are drawn in Section 6.

\section{Fundamentals of Numerical Methods for the Interfaces}

2.1. The Contact Problem. With reference to Figure 1, we consider the contact of two deformable bodies, where the problem domain $\Omega$ is divided into two subdomains $\Omega_{1}$ (bounded by $\Gamma_{1}$ ) and $\Omega_{2}$ (bounded by $\Gamma_{2}$ ). The bodies are fixed at $\Gamma_{u}=\Gamma_{1 u} \cup \Gamma_{2 u}$ and subjected to boundary traction $t$ at $\Gamma_{t}=\Gamma_{1 t} \cup \Gamma_{2 t} . \Gamma_{1 c}$ and $\Gamma_{2 c}$ are the potential contacting boundaries of $\Omega_{1}$ and $\Omega_{2}$, respectively, while $\Gamma_{c}$ denotes the exact contact part on $\Gamma_{1 c}$ and $\Gamma_{2 c}$.

2.2. Interface Element Method. For the interface element method (Figure 2), the interface conditions are described by

$$
\left.\boldsymbol{\sigma} \cdot \mathbf{n}\right|_{\Gamma_{1 c} \cap \Gamma_{c}}=\left.\boldsymbol{\sigma} \cdot \mathbf{n}\right|_{\Gamma_{2 c} \cap \Gamma_{c}}
$$

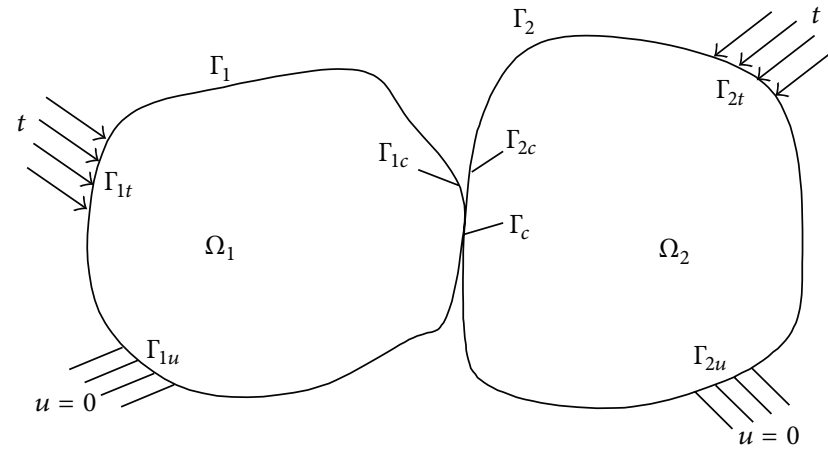

Figure 1: Contact of two deformable bodies.

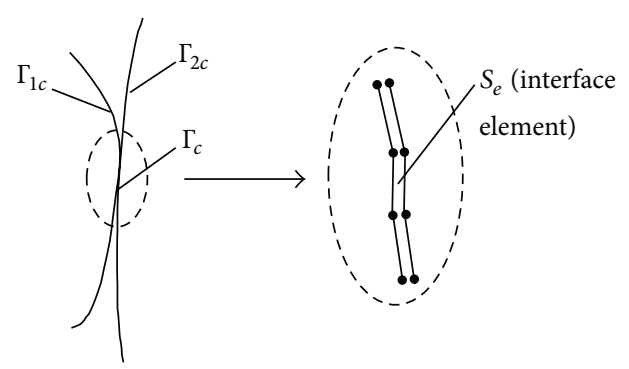

Figure 2: Interface element method.

where $\boldsymbol{\sigma}$ is the stress tensor, $\mathbf{n}$ is the outward normal, and $[\delta \mathbf{u}]$ denotes the increment of a displacement jump $[2,6]$. Such a problem has the following weak form:

$$
\begin{aligned}
& \left\{\int_{\Omega_{1}}\{\delta \boldsymbol{\varepsilon}\}^{T}\{\boldsymbol{\sigma}\} \mathrm{d} \Omega-\int_{\Omega_{1}}\{\delta u\}^{T}\{b\} \mathrm{d} \Omega-\int_{\Gamma_{1 t}}\{\delta u\}^{T}\{t\} \mathrm{d} \Gamma\right\} \\
& \quad+\left\{\int_{\Omega_{2}}\{\delta \boldsymbol{\varepsilon}\}^{T}\{\boldsymbol{\sigma}\} \mathrm{d} \Omega-\int_{\Omega_{2}}\{\delta u\}^{T}\{b\} \mathrm{d} \Omega-\int_{\Gamma_{2 t}}\{\delta u\}^{T}\{t\} \mathrm{d} \Gamma\right\} \\
& +\int_{\Gamma_{c}}\{\boldsymbol{\sigma}\}[\delta \mathbf{u}] \mathrm{d} \Gamma=0,
\end{aligned}
$$

where $\boldsymbol{\varepsilon}$ is the strain tensor, $u$ is the displacement, $b$ is the body force, and $t$ is the boundary traction. This weak form is composed of three terms:

$$
\pi_{1}+\pi_{2}+\pi_{\text {interface }}=0
$$

where $\pi_{1}$ denotes the terms in the first bracket to express the potential in $\Omega_{1}, \pi_{2}$ denotes the terms in the second bracket to express the potential in $\Omega_{2}$, and $\pi_{\text {interface }}$ denotes the last term to express the potential along the interface $\Gamma_{c}$. On discretizing the interface term $\pi_{\text {interface }}$, the element stiffness is obtained as

$$
K_{\text {in }}^{e}=\int_{S_{e}} T^{T} N_{u}^{T}[\bar{D}]_{e p} N_{u} T \mathrm{~d} S,
$$

where $T$ and $N_{u}$ are the transformation matrix and shape function of the interface element $S_{e}$. The material matrix $[\delta \mathbf{u}] \geq 0$, 


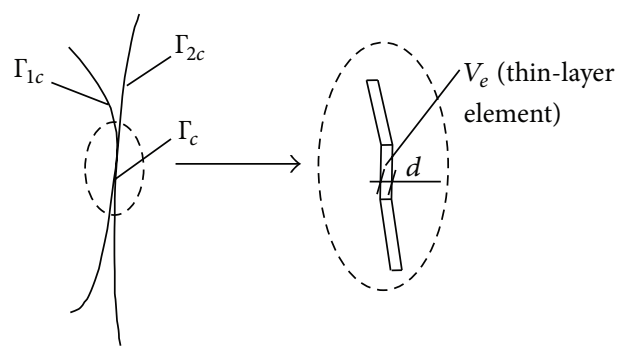

Figure 3: Thin-layer element method.

$[\bar{D}]_{e p}$ is defined using the following constitutive law of an interface [6]:

$$
\begin{aligned}
& \left\{\begin{array}{c}
\Delta \sigma_{n} \\
\Delta \tau
\end{array}\right\}=[\bar{D}]_{e p}\left\{\begin{array}{l}
{\left[\Delta u_{n}\right]} \\
{\left[\Delta u_{s}\right]}
\end{array}\right\}, \\
& {[\bar{D}]_{e p}=\left[\begin{array}{ll}
k_{n} & k_{n s} \\
k_{s n} & k_{s}
\end{array}\right] \text {, }}
\end{aligned}
$$

where $\sigma_{n}, \tau$ are the normal and shear stresses, $u_{n}, u_{s}$ are the normal and shear displacements, $k_{n}, k_{s}$ are the normal and shear stiffness, and $k_{s n}, k_{n s}$ are the coupling stiffnesses between normal and shear deformations.

Goodman et al. [2] did not consider the coupling effect between normal and shear deformations. They took the material matrix as

$$
[\bar{D}]_{e p}=\left[\begin{array}{cc}
k_{n} & 0 \\
0 & k_{s}
\end{array}\right]
$$

and the shear stiffness $k_{s}$ as

$$
k_{s}=k_{1} \gamma_{w}\left(\frac{\sigma_{n}}{P_{a}}\right)^{n_{1}}\left(1-\frac{R_{f 1} \tau}{\sigma_{n} \operatorname{tg} \phi}\right)^{2},
$$

where $k_{1}$ and $n_{1}$ are two parameters, $\sigma_{n}$ is the normal stress on the interface, $\tau$ is the shear stress along the interface, $P_{a}$ is the atmospheric pressure, $\gamma_{w}$ is the unit weight of water, $R_{f 1}$ is the failure ratio, and $\phi$ is the angle of internal friction. $k_{1}$, $n_{1}, R_{f 1}$, and $\phi$ are the four parameters to be determined from direct shear tests. The normal stiffness $k_{n}$ is usually given a large number when the interface element is in compression and a small number when in tension.

2.3. Thin-Layer Element Method. In this method, an interface is treated as a thin-layer solid element (Figure 3). This thin layer is given a relatively low modulus and can experience large deformation [8-11]. The problem shown in Figure 1 with a thin layer has the following weak form:

$$
\pi_{1}+\pi_{2}+\pi_{\text {thin }}=0
$$

where the term on the thin layer, $\pi_{\text {thin }}$, is given by

$$
\pi_{\text {thin }}=\int_{V_{L}}\{\delta \boldsymbol{\varepsilon}\}^{T}\{\boldsymbol{\sigma}\} \mathrm{d} V,
$$

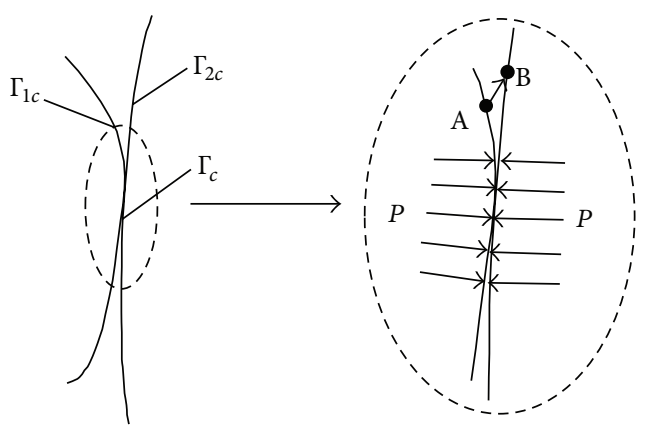

FIGURE 4: Contact analysis method.

with $V_{L}$ denoting the domain of interface $\Gamma_{c}$. If $V_{L}$ has a finite thickness of $d$, the element stiffness of thin layer element $V_{e}$ is

$$
K_{\mathrm{th}}^{e}=\int_{V_{e}} B^{T} D B \mathrm{~d} V \underset{d \ll S_{e}}{\cong} d \int_{S_{e}} B^{T} D B \mathrm{~d} S,
$$

where $B$ is the strain matrix, $D$ is the material matrix, and $S_{e}$ is the element length. Previous studies revealed that the accuracy of element stiffness is sensitive to the aspect ratio $d / S_{e}$. When the aspect ratio varies in the range of $0.01-0.1$, slippage is modeled quite accurately [8-11].

\subsection{Contact Analysis Method}

2.4.1. Contact of Two Deformable Bodies. As shown in Figure 4, the potential contact boundaries are $\Gamma_{1 c}$ in $\Gamma_{1}$ and $\Gamma_{2 c}$ in $\Gamma_{2}$, while the exact contact boundary is denoted as interface $\Gamma_{c}$, which is usually unknown beforehand. The weak form of each deformable body is expressed individually as follows.

For deformable body $\Omega_{1}$

$$
\begin{gathered}
\left\{\int_{\Omega_{1}}\{\delta \boldsymbol{\varepsilon}\}^{T}\{\boldsymbol{\sigma}\} \mathrm{d} \Omega-\int_{\Omega_{1}}\{\delta u\}^{T}\{b\} \mathrm{d} \Omega-\int_{\Gamma_{1 t}}\{\delta u\}^{T}\{t\} \mathrm{d} \Gamma\right\} \\
-\int_{\Gamma_{c}}\{\delta u\}^{T}\{P\} \mathrm{d} \Gamma=0 .
\end{gathered}
$$

For deformable body $\Omega_{2}$

$$
\begin{gathered}
\left\{\int_{\Omega_{2}}\{\delta \boldsymbol{\varepsilon}\}^{T}\{\boldsymbol{\sigma}\} \mathrm{d} \Omega-\int_{\Omega_{2}}\{\delta u\}^{T}\{b\} \mathrm{d} \Omega-\int_{\Gamma_{2 t}}\{\delta u\}^{T}\{t\} \mathrm{d} \Gamma\right\} \\
-\int_{\Gamma_{c}}\{\delta u\}^{T}\{P\} \mathrm{d} \Gamma=0
\end{gathered}
$$

where $\{P\}$ is the interaction force. Upon discretizing the weak forms in (11) and (12), the following discrete system equation is obtained for each deformable body:

$$
\begin{array}{ll}
K_{11} u_{1}+K_{12} u_{12}+L_{1} P=f_{1} & \text { for } \Omega_{1}, \\
K_{22} u_{2}+K_{21} u_{21}+L_{2} P=f_{2} & \text { for } \Omega_{2},
\end{array}
$$


where $u_{1}$ and $u_{2}$ are the displacement increments in $\Omega_{1}$ and $\Omega_{2}$ whose boundaries exclude the exact contact boundary, $u_{12}$ is the displacement increment along $\Gamma_{1 c}, u_{21}$ is the displacement increment along $\Gamma_{2 c}$, and $P$ is the interaction force along the contact interface $\Gamma_{c}$. It can be proved that $P$ is equivalent to the Lagrange multiplier $[17,18]$.

When the two bodies are not in contact, one body imposes no constraints on the other, and thus (13) and (14) are independent of each other and $P \equiv 0$. The displacement increments $u_{1}$ and $u_{12}$ are solved using (13), while $u_{2}$ and $u_{21}$ are determined by (14).

When the two bodies are in contact, one deformable body imposes constraints on the other. At this time, $u_{12}$ and $u_{21}$ are no longer independent, and $P$ is introduced as an unknown. The contact boundary should satisfy the kinematic and dynamic constraints. As shown in Figure 4, if point A on $\Gamma_{1 c}$ coincides with point $\mathrm{B}$ on $\Gamma_{2 c}$, the kinematic constraint is expressed as [12]

$$
\left(u_{12}^{\mathrm{A}}-u_{21}^{\mathrm{B}}\right) \eta \leq \mathrm{TOL},
$$

where $\eta$ is the directional cosine at the contact point and TOL is the closure distance or contact tolerance. The dynamic condition is Coulomb's friction law in our computation:

$$
P_{t} \leq-\mu \cdot P_{n} \cdot \eta_{t}
$$

where $P_{t}$ is the tangential friction traction force, $P_{n}$ is the normal traction force, $\mu$ is the friction coefficient, and $\eta_{t}$ is the tangential vector in the direction of relative velocity. Therefore, the unknowns $u_{1}, u_{12}, u_{2}, u_{21}, P$, and $\Gamma_{c}$ can be completely solved from (13)-(16).

2.4.2. Strategy of Searching Contact Points. The contact interface $\Gamma_{c}$ is the key unknown in the contact problem. Zhang et al. [12] used a typical node-edge contact mode to implement contact detection at the element level. The disadvantage of this node-edge contact mode is that the accuracy is low. This study uses curve fitting; that is, the point interpolation method $[14,15]$, to detect the exact contact interface $\Gamma_{c}$. The numerical procedure is as follows.

Step 1. Assume potential contact interfaces $\Gamma_{1 c}$ on $\Omega_{1}$ and $\Gamma_{2 c}$ on $\Omega_{2}$.

Step 2. Locate the nodal points on the interfaces $\Gamma_{1 c}$ and $\Gamma_{2 c}$. There are $M$ nodes on $\Gamma_{1 c}$, denoted by $x_{11}, x_{12}$, $\ldots, x_{1 i}, \ldots, x_{1 M}$ and $N$ nodes on $\Gamma_{2 c}$, denoted by $x_{21}, x_{22}$, $\ldots, x_{2 i}, \ldots, x_{2 N}$

Step 3. Interpolate these nodes to form the boundary lines using the radial point interpolation method $[14,15]$.

One has

$$
x=\sum_{i=1}^{M} N_{1 i} x_{1 i}, \quad x=\sum_{j=1}^{N} N_{2 j} x_{2 j},
$$

where the shape functions $N_{1 i}, N_{2 j}$ are determined using point interpolation methods $[14,15]$.
Step 4. Establish the distance function $\delta$ along either boundary line. The point is not in contact when $\delta>$ TOL. Otherwise, the point is in contact with the other boundary. Identify the exact contact points through (17). Iterate the same procedure to find out the entire contact boundary.

Step 5. Iterate FEM computation to satisfy the equilibrium of two deformable bodies and the contact boundary conditions.

Step 6. Update nodal coordinates on the contact boundary. Carry out the next step computation, and return to Step 3 for the same search procedure for the contact points.

\section{Constitutive Models for Dam Materials}

3.1. EB Model for Rockfill Materials. Rockfill materials and soil masses behave with strong nonlinearity because of the high stress levels in dams. This nonlinearity is described by the following incremental Hooke's law:

$$
\begin{aligned}
\left\{\begin{array}{l}
d \sigma_{x} \\
d \sigma_{y} \\
d \tau_{x y}
\end{array}\right\}=[D]\left\{\begin{array}{c}
d \varepsilon_{x} \\
d \varepsilon_{y} \\
d \gamma_{x y}
\end{array}\right\} \\
=\left[\begin{array}{ccc}
B_{t}+\frac{4}{3} G_{t} & B_{t}-\frac{2}{3} G_{t} & 0 \\
B_{t}-\frac{2}{3} G_{t} & B_{t}+\frac{4}{3} G_{t} & 0 \\
0 & 0 & 2 G_{t}
\end{array}\right]\left\{\begin{array}{c}
d \varepsilon_{x} \\
d \varepsilon_{y} \\
d \gamma_{x y}
\end{array}\right\},
\end{aligned}
$$

where $B_{t}$ is the bulk modulus, $G_{t}=3 B_{t} E_{t} /\left(9 B_{t}-E_{t}\right)$ is the shear modulus, and $E_{t}$ is the deformation modulus. The Duncan EB model [16] gives the deformation modulus $E_{t}$ as follows:

$$
E_{t}=k \cdot P_{a}\left(\frac{\sigma_{3}}{P_{a}}\right)^{n}\left[1-R_{f} \frac{(1-\sin \phi)\left(\sigma_{1}-\sigma_{3}\right)}{2 c \cdot \cos \phi+2 \sigma_{3} \sin \phi}\right]^{2},
$$

where $\left(\sigma_{1}-\sigma_{3}\right)$ is the deviatoric stress, $\sigma_{3}$ is the confining pressure, $c$ is the cohesion intercept, $\phi$ is the angle of internal friction, $R_{f}$ is the failure ratio, $P_{a}$ is the atmospheric pressure, and $k$ and $n$ are constants.

In the computation, the rockfill material has $c=0$ and a variable angle of internal friction $\phi$

$$
\phi=\phi_{0}-\Delta \phi \log \left(\frac{\sigma_{3}}{P_{a}}\right),
$$

where $\phi_{0}$ and $\Delta \phi$ are two constants. Another parameter, bulk modulus $B_{t}$, is assumed to be

$$
B_{t}=k_{b} P_{a}\left(\frac{\sigma_{3}}{P_{a}}\right)^{m},
$$

where $k_{b}$ and $m$ are constants.

3.2. Linear Elastic Model for the Concrete Face Slab. A linear elastic model with Young's modulus $E$ and Poisson ratio $v$ is used to describe the mechanical properties of the concrete face slab. No failure is allowed. 


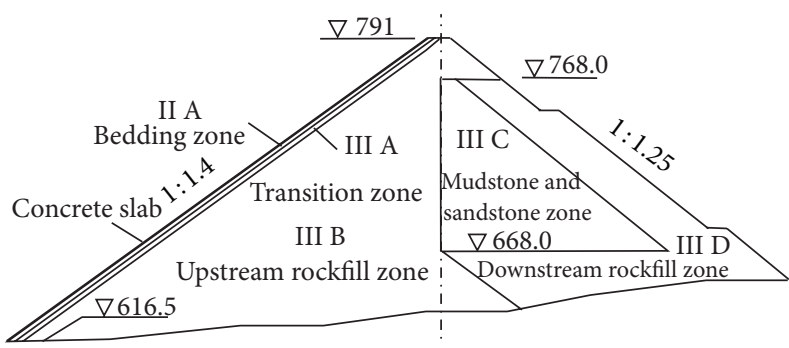

(a) Material zoning

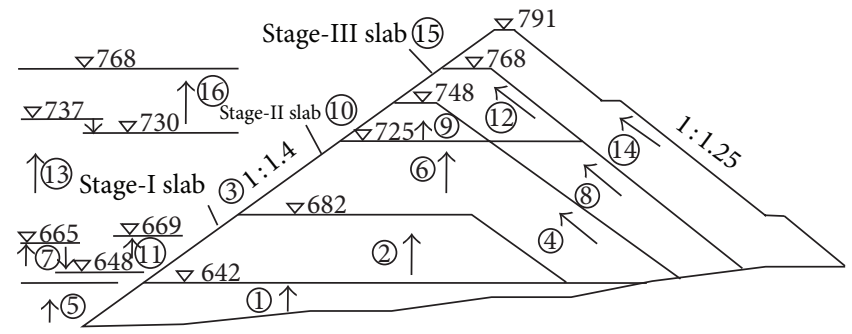

(b) Construction stages

FIgURE 5: Material zones and construction stages of Tianshengqiao-I CFRD.

TABLE 1: Design parameters of dam materials.

\begin{tabular}{lcccc}
\hline Mat. number & Mat. description & $\begin{array}{c}\text { Max. particle size } \\
(\mathrm{cm})\end{array}$ & $\begin{array}{c}\text { Dry unit weight } \\
\left(\mathrm{KN} / \mathrm{m}^{3}\right)\end{array}$ & Void ratio $(\%)$ \\
\hline IIA & Processed limestone & 8 & 22.0 & 19 \\
IIIA & Limestone & 30 & 21.5 & 21 \\
IIIB & Limestone & 80 & 21.2 & 22 \\
IIIC & Mudstone and sandstone & 80 & 21.5 & 22 \\
IIID & Limestone & 160 & 20.5 & 24 \\
\hline
\end{tabular}

\section{Computation Models and Parameters}

4.1. Tianshengqiao-I Concrete-Faced Rockfill Dam Project. The Tianshengqiao-I hydropower project is on the Nanpan River in southwestern China [12]. Its water retaining structure is a concrete-faced rockfill dam, $178 \mathrm{~m}$ high and $1104 \mathrm{~m}$ long. The rockfill volume of the dam body is about 18 million $\mathrm{m}^{3}$, and the area of the concrete face is $173,000 \mathrm{~m}^{2}$. A surface chute spillway on the right bank allows a maximum discharge of $19,450 \mathrm{~m}^{3} / \mathrm{s}$. The tunnel in the right abutment is used for emptying the reservoir during operation. The left abutment has four power tunnels and a surface powerhouse with a total capacity of 1,200 MW. Material zoning and construction stages are shown in Figure 5. The design parameters of the dam materials are listed in Table 1, and the details of each construction stage are given in Table 2.

4.2. Computation Section, Procedure, and Material Parameters. A two-dimensional finite element analysis was performed [19]. The maximum cross-section (section $0+630 \mathrm{~m}$ ), which is in the middle of the riverbed, was taken for computation. Figure 6(a) shows the finite element mesh for the contact analysis method. It has a total of 402 four-node elements in the dam body and 46 four-node elements in the concrete face slab (the concrete face slab is divided into two layers of elements). The mesh for the interface element method is shown in Figure 6(b), where a row of interface elements is placed along the interface between the concrete face slab and the cushion layer. This mesh model has 23 additional interface elements compared to the mesh for the contact analysis model. If the interface elements in Figure 6(b) are assigned a thickness of $0.3 \mathrm{~m}$, the finite element mesh for the thin-layer element method is obtained. Because the length of each element is $12 \mathrm{~m}$, the thin-layer elements have an aspect
TABLE 2: Construction stages and time.

\begin{tabular}{lcc}
\hline Filling step & Time & Remark \\
\hline (1) & $1996.01-1996.06$ & Fill dam body \\
(2) & $1996.07-1997.02$ & Fill dam body \\
(3) & $1997.03-1997.05$ & Cast Phase 1 concrete slab \\
(4) and (6) & $1997.02-1997.10$ & Fill dam body \\
(5) & $1997.05-1997.05$ & Water level rises \\
(7) & $1997.06-1997.10$ & Water level fluctuation \\
(8) and (9) & $1997.11-1998.01$ & Fill dam body \\
(10) & $1997.12-1998.05$ & Cast Phase 2 concrete slab \\
(11) & $1997.11-1997.12$ & Water level rises \\
(12) & $1998.02-1998.08$ & Fill dam body \\
(13) & $1998.06-1998.07$ & Water level rises \\
(14) & $1998.08-1999.01$ & Fill dam body \\
(15) & $1999.01-1999.05$ & Cast Phase 3 concrete slab \\
(16) & $1999.06-1999.09$ & Store water \\
\hline
\end{tabular}

ratio of 0.025 , in the range of $0.01-0.1$ [8-11]. The previous mesh models show that the dam body and concrete face slab can be meshed independently for the contact analysis method. This may produce nonmatching nodes on both sides of the interface [15]. However, the thin-layer element and interface element methods usually require matching nodes on both sides of the interface. This model sets zero displacements along the rock base [12].

The computational procedure follows exactly the construction stages shown in Figure 5(b). First, blocks (1) and (2) of the dam body were built up to El.682 m. In each block, layer-by-layer elements were activated to simulate the construction process, and the midpoint stiffness [20] was used for the nonlinear constitutive model. Before placement 


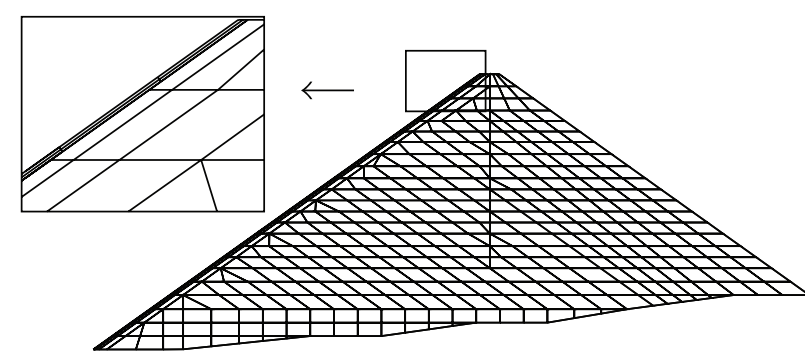

(a) For the contact analysis method

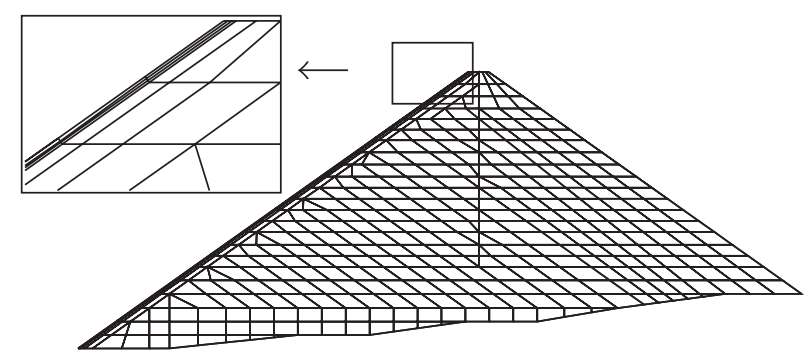

(b) For the interface element method

FIGURE 6: Two-dimensional finite element mesh.

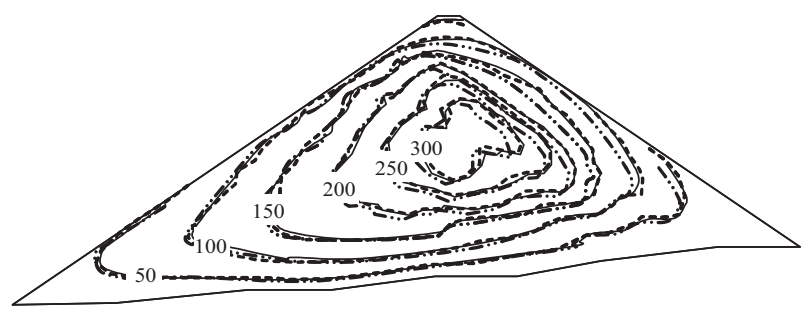

- Interface element method

- - Contact analysis method

...... Thin-layer element method

(a) Comparison of the interface element, contact analysis, and thin-layer element methods

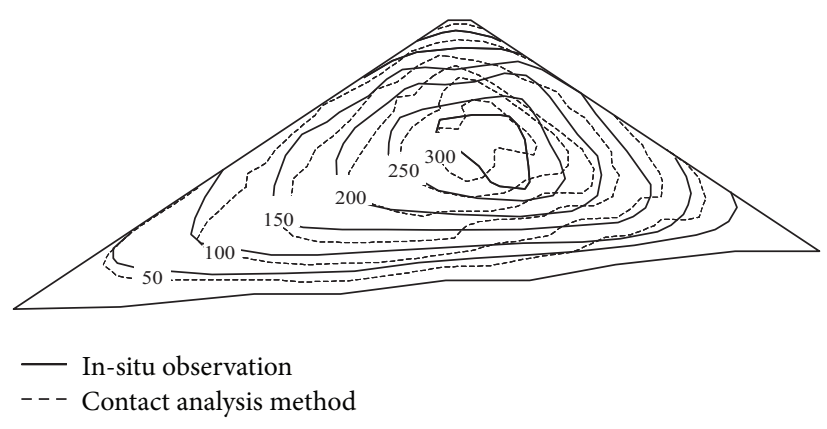

(b) Comparison of the contact analysis method and in-situ observation

Figure 7: Contours of settlement in the dam body in August 1999 (unit: cm).

of the freshly cast stage-I slab, the calculated displacements of the dam body were set to zero, and the calculated stresses were retained. The elements of stage-I slab (3) were then activated, and dam construction continued. The impounding process was simulated by increasing the water level by $10 \mathrm{~m}$ in each increment. The same procedure was repeated until completion of the whole dam body.

The concrete face slab had an elastic modulus of $3 \times$ $10^{4} \mathrm{MPa}$ and a Poisson's ratio of 0.2. Table 3 gives the computational parameters of the rockfill materials for the EB model. An elastic modulus of $6 \mathrm{MPa}$ and Poisson's ratio of 0.2 were used for the materials in the thin-layer elements. The computational parameters for the Goodman interface model are listed in Table 4.

\section{Comparison of the Three Methods}

5.1. Deformation of the Dam Body in August 1999. The deformation of the dam body in August 1999 (water level: 768 m) was predicted by the previous three numerical methods. Figure 7 compares the contours of the predicted settlement using these numerical methods with in-situ observations. The in-situ observation data used in this study were provided by the HydroChina Kunming Engineering Corporation [21]. Horizontal displacements were measured using indium steel wire alignment horizontal displacement meters, and settlements were measured using water level settlement gauges. As shown in Figure 7, the three numerical methods provided almost identical results and agreed reasonably with the in-situ observation data.

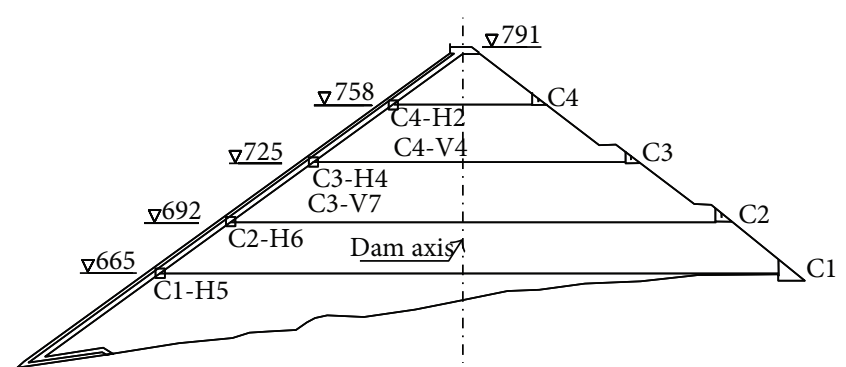

FIGURE 8: In-situ observation points along the interface at $0+630$ section.

Figure 8 shows the locations of the observation points along the interface, where $\mathrm{C} 1-\mathrm{H} 5, \mathrm{C} 2-\mathrm{H} 6, \mathrm{C} 3-\mathrm{H} 4$, and $\mathrm{C} 4-$ $\mathrm{H} 2$ are the horizontal displacement measurement points and C3-V7 and C4-V4 are the settlement measurement points. The settlement-time curves and horizontal displacementtime curves at typical observation points are displayed in Figures 9 and 10, respectively. The in-situ observations are also plotted for comparison. The three numerical methods predicted almost the same settlements and were in reasonable agreement with the in-situ observations. The horizontal displacements predicted by the three numerical methods were also similar and agreed reasonably with the in-situ observations.

5.2. Separation of the Concrete Face Slab from the Cushion Layer. Figures 11 and 12 show the separation of the concrete 
TABLE 3: Computational parameters for the rockfill materials.

\begin{tabular}{lcccccccc}
\hline Mat. number & Density $\left(\mathrm{kg} / \mathrm{m}^{3}\right)$ & $\phi^{\prime}\left[^{\circ}\right]$ & $\Delta \phi\left[^{\circ}\right]$ & $k$ & $n$ & $R_{f}$ & $k_{b}$ & $m$ \\
\hline IIA & 2200 & 50.6 & 7.0 & 1000 & 0.35 & 0.71 & 450 & 0.24 \\
IIIA & 2100 & 52.5 & 8.0 & 900 & 0.36 & 0.76 & 400 & 0.19 \\
IIIB & 2100 & 51.0 & 13.0 & 564 & 0.35 & 0.85 & 204 \\
IIID & 2050 & 51.0 & 13.5 & 432 & 0.30 & 0.80 & 300 & -0.18 \\
IIIC & 2150 & 45.0 & 10.0 & 250 & 0.25 & 0.73 & 125 & 0.00 \\
\hline
\end{tabular}

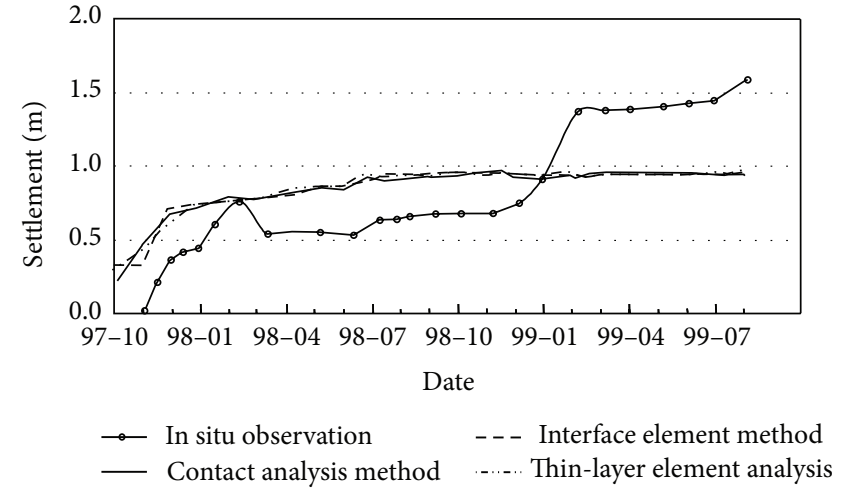

(a) C3-V7 point

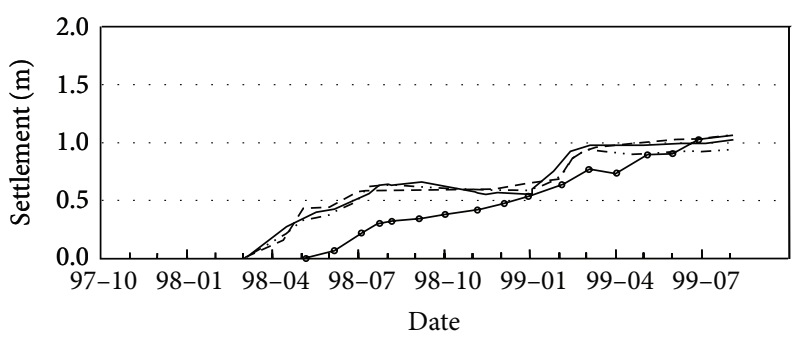

$\rightarrow$ In situ observation _ Interface element method - - - Contact analysis method _...... Thin-layer element method

(b) C4-V4 point

FIgURE 9: Settlement of the dam body along the interface.

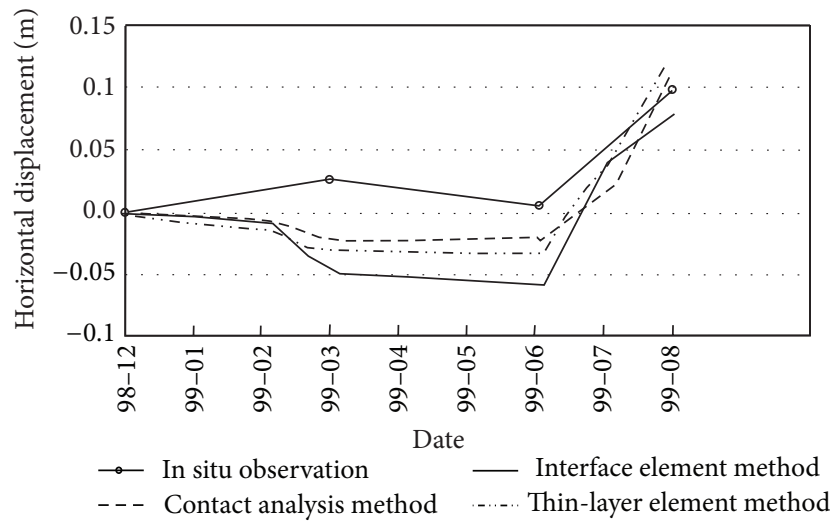

(a) Cl-H5 point

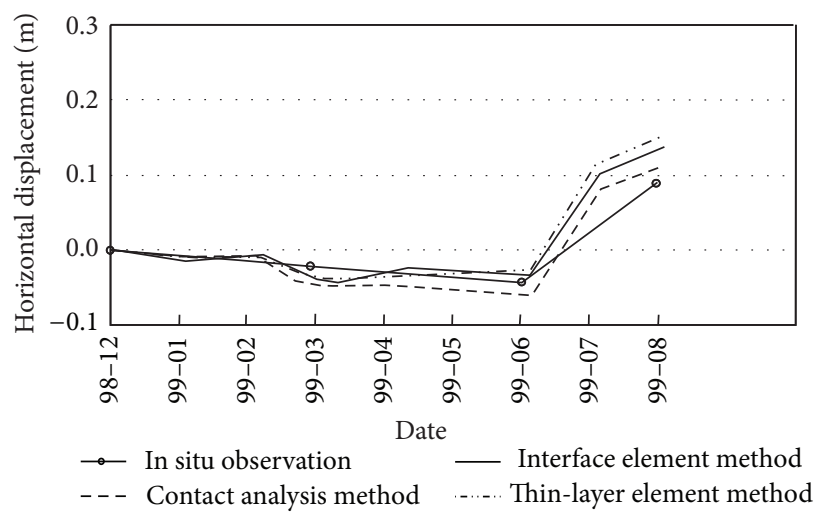

(c) C3-H4 point

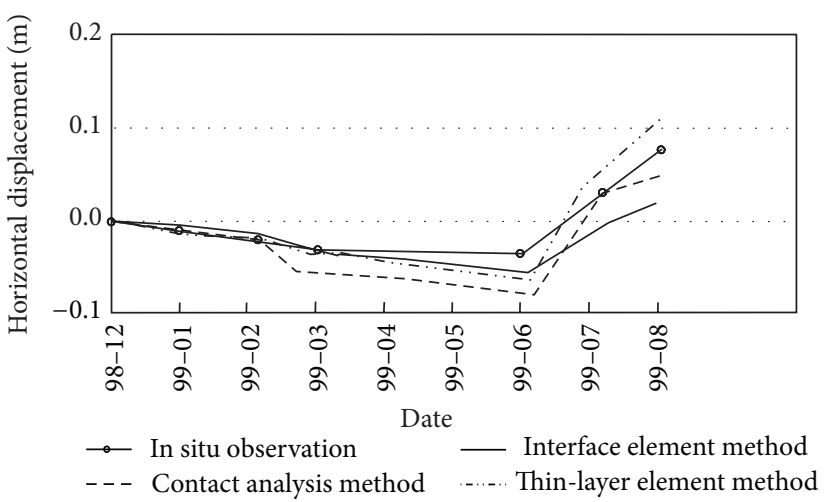

(b) C2-H6 point

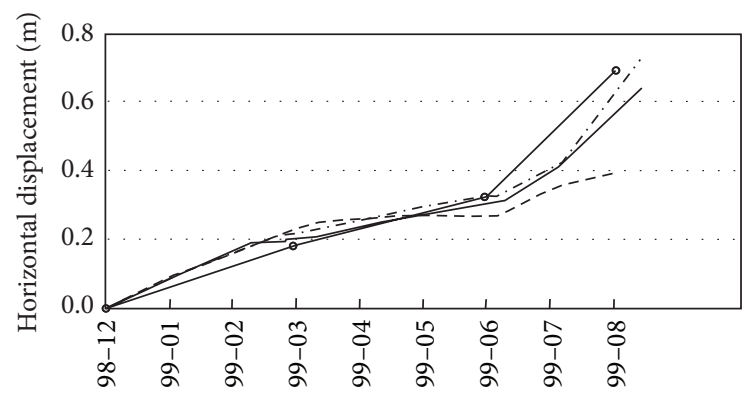

$\therefore$ In situ observation Date __ Interface element method - - Contact analysis method -..... Thin-layer element method

(d) $\mathrm{C} 4-\mathrm{H} 2$ point

FIGURE 10: Horizontal displacement of the dam body along the interface. 


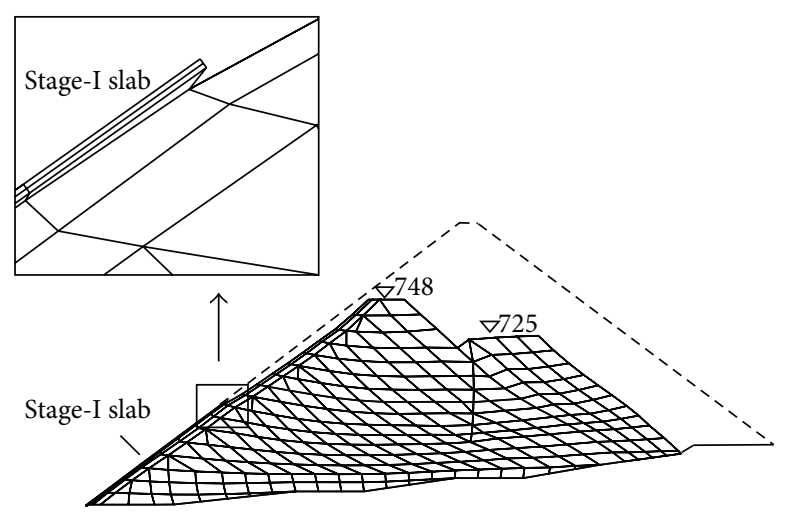

(a) Separation of the stage-I slab

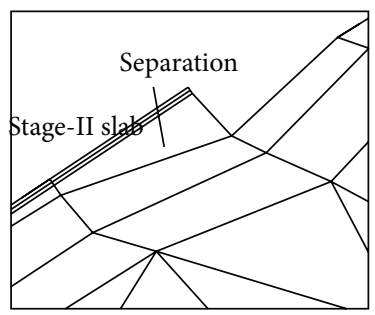

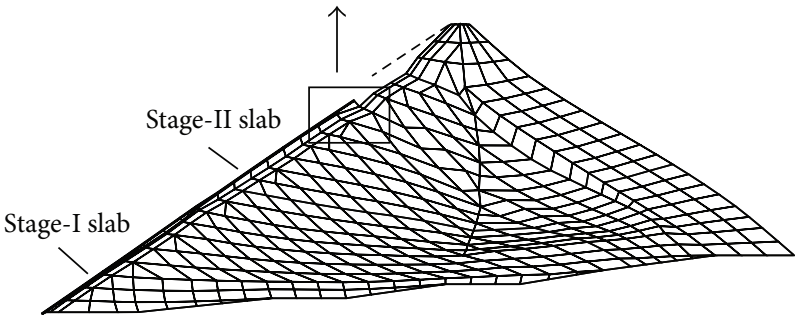

(b) Separation of the stage-II slab

Figure 11: Separation of the slab from the cushion layer at different stages (interface element method).

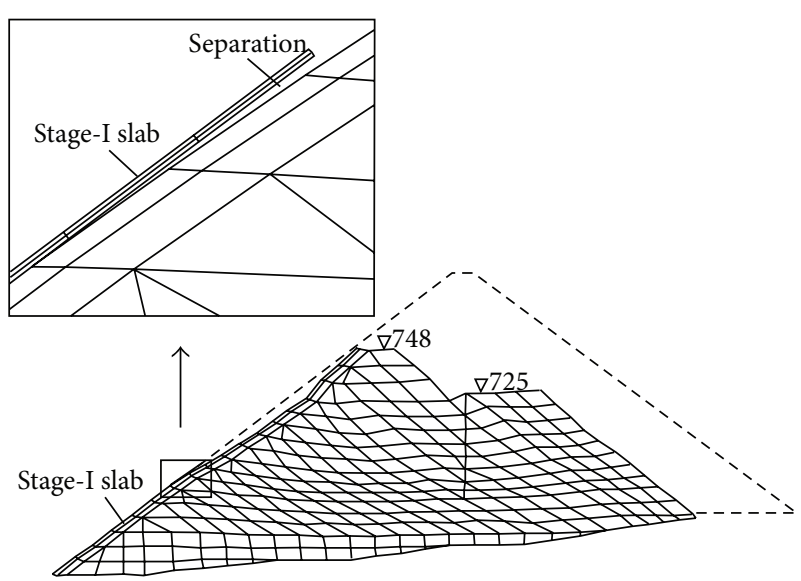

(a) Separation of the stage-I slab

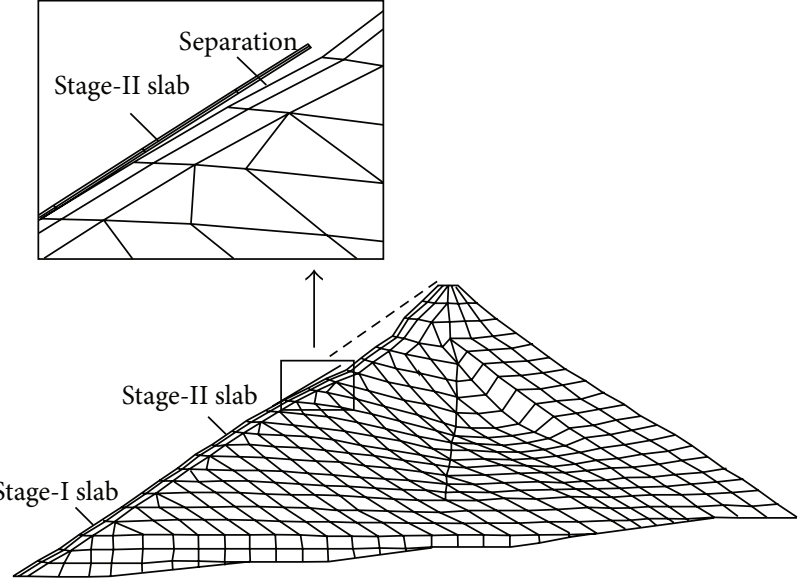

(b) Separation of the stage-II slab

Figure 12: Separation of the slab from the cushion layer at different stages (contact analysis method).

TABle 4: Parameters of the Goodman interface model.

\begin{tabular}{cccccc}
\hline$\phi\left[{ }^{\circ}\right]$ & $k_{1}$ & $n_{1}$ & $R_{f 1}$ & \multicolumn{2}{c}{$k_{n}(\mathrm{MPa})$} \\
& & & & Compression & Tension \\
\hline 30 & 1000 & 0.3 & 1 & 10000 & 1 \\
\hline
\end{tabular}

face slab from the cushion layer at different construction stages, predicted by the interface element and contact analysis methods, respectively. Table 5 compares the maximum opening width and depth predicted by the three numerical methods with the in-situ observations. The opening width was measured using a TSJ displacement meter, and the depth was measured manually using a ruler.

The contact analysis method predicted a maximum opening width of $0.13 \mathrm{~m}$ and a depth of $8.0 \mathrm{~m}$ for the stageI slab, which were in good agreement with the in-situ observations. The thin-layer element and interface element
TABLE 5: Comparison of the maximum openings.

\begin{tabular}{lcccc}
\hline & \multicolumn{2}{c}{ Stage-I slab } & \multicolumn{2}{c}{ Stage-II slab } \\
& Width (m) & Depth $(\mathrm{m})$ & Width $(\mathrm{m})$ & Depth $(\mathrm{m})$ \\
\hline $\begin{array}{l}\text { In-situ observation } \\
\begin{array}{l}\text { Contact analysis } \\
\text { method }\end{array}\end{array}$ & 0.15 & 7.2 & 0.10 & 5.0 \\
$\begin{array}{l}\text { Thin-layer element } \\
\text { method* }\end{array}$ & 0 & 8.0 & 0.40 & 14.0 \\
$\begin{array}{l}\text { Interface element } \\
\text { method }^{*}\end{array}$ & 0 & 0 & 0.05 & 13.2 \\
\hline
\end{tabular}

${ }^{*}$ The depth of the tensile stress zone in the interface/thin-layer element is taken as the opening depth, and the relative displacement is taken as the opening width.

methods predicted no opening for the stage-I slab. At the completion of dam body construction, the contact analysis 


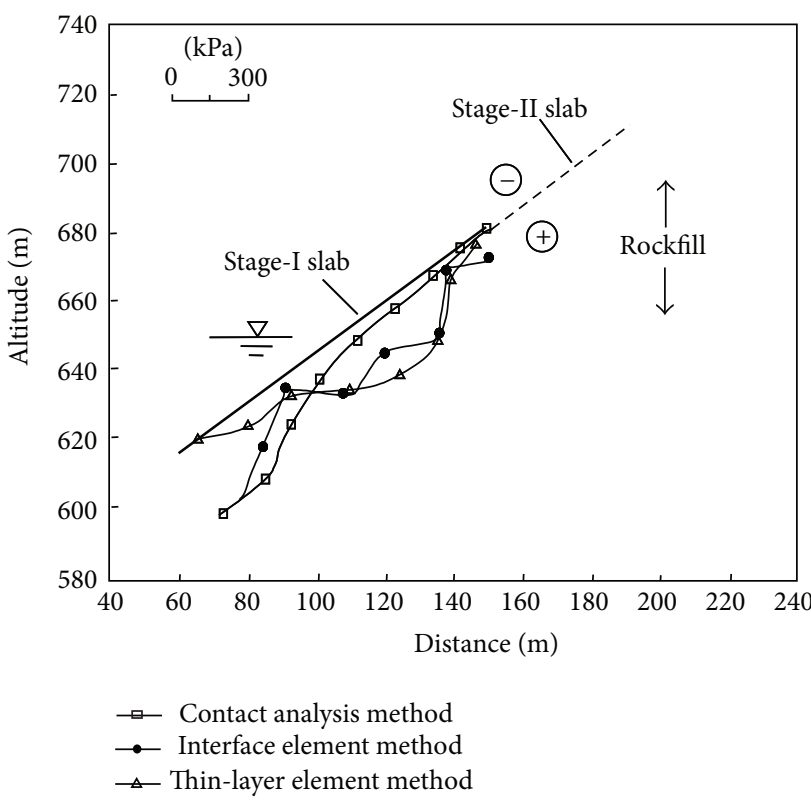

(a) Before casting the stage-II slab

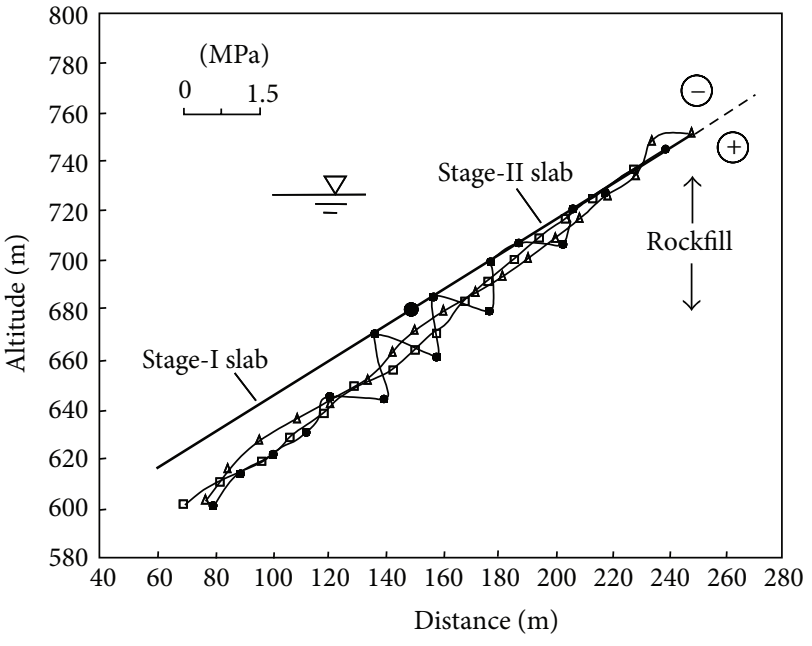

$\rightarrow$ Contact analysis method
$\rightarrow$ Interface element method
$\triangle-$ Thin-layer element method

(b) Completion of the dam body construction

FIGURE 13: Comparison of normal contact stress along the interface.

method predicted a maximum opening width of $0.40 \mathrm{~m}$ and a depth of $14.0 \mathrm{~m}$ for the stage-II slab, while the in-situ observations were much smaller with an opening width of $0.1 \mathrm{~m}$ and an opening depth of $5.0 \mathrm{~m}$. The opening widths predicted using the thin-layer element and interface element methods were closer to the in-situ observations. However, the interface element method predicted a much larger opening depth.

As shown in Figure 11, the opening width and depth were mesh-size dependent for both the thin-layer element and interface element methods because they used element information to determine the separation. The opening depth was the depth of the tensile stress zone, and the opening width was the relative displacement. Therefore, the opening width and depth obtained were used only for reference. Conversely, the contact analysis method regarded the concrete face slab and dam body as independent deformable bodies, and thus the separation could be directly calculated and was independent of mesh size as shown in Figure 12. Therefore, it was concluded that the contact analysis method was reliable and accurate in the prediction of the opening width and depth. In summary, the contact analysis method was a better choice for simulating the separation (opening width and depth) of the concrete face slab from the cushion layer.

5.3. Normal Contact Stress along the Interface. The normal contact stress along the interface is compared in Figure 13 for the three numerical methods. Figure 13(a) shows the contact stress immediately before casting the stage-II slab and Figure 13(b) at the completion of dam body construction. As shown in Figure 13(a), the maximum normal stress predicted by the thin-layer element method occurs at the middle of the interface between the stage-I slab and the cushion layer, which is not reasonable because the self-weight of the
stage-I slab and water pressure should produce a larger normal stress at the bottom as predicted by the contact analysis method. At this stage, the thin-layer element method failed to predict any separation. Furthermore, thin-layer element method predicted a tensile stress zone at the top of the stage-II slab after completion of the dam body construction (Figure 13(b)). Physically, no tensile stress should exist if separation of the two materials occurs. Because the thinlayer element was basically a solid element, it was unsuitable for separation simulation [9]. The interface element method predicted oscillatory normal contact stress at both stages, and the elimination of such oscillation was difficult $[3,22]$. In addition, the interface element method could not predict the separation before casting the stage-II slab, and the opening depth was mesh-size dependent. Therefore, both the thinlayer element and interface element methods could not correctly compute the contact stress or the separation.

5.4. Stresses in the Concrete Face Slab. The stress distribution in the concrete face slab, which was complex because of the deflection of the concrete face slab, was important to the development of cracks. The shear and normal stresses in the concrete face slab at the completion of dam body construction predicted by the three numerical methods, are compared in Figure 14. Both normal and shear stresses predicted by the interface element method were oscillatory and nonzero at the top of the slab. The thin-layer element method predicted less oscillatory stresses; however, its normal and shear stresses were also nonzero at the top of the concrete face slab. The magnitude of the stresses predicted by the contact analysis method was much lower than the other two methods, and the normal and shear stresses were zero at the top of the slab. Moreover, the stress distributions for the concrete face slab looked reasonable. 


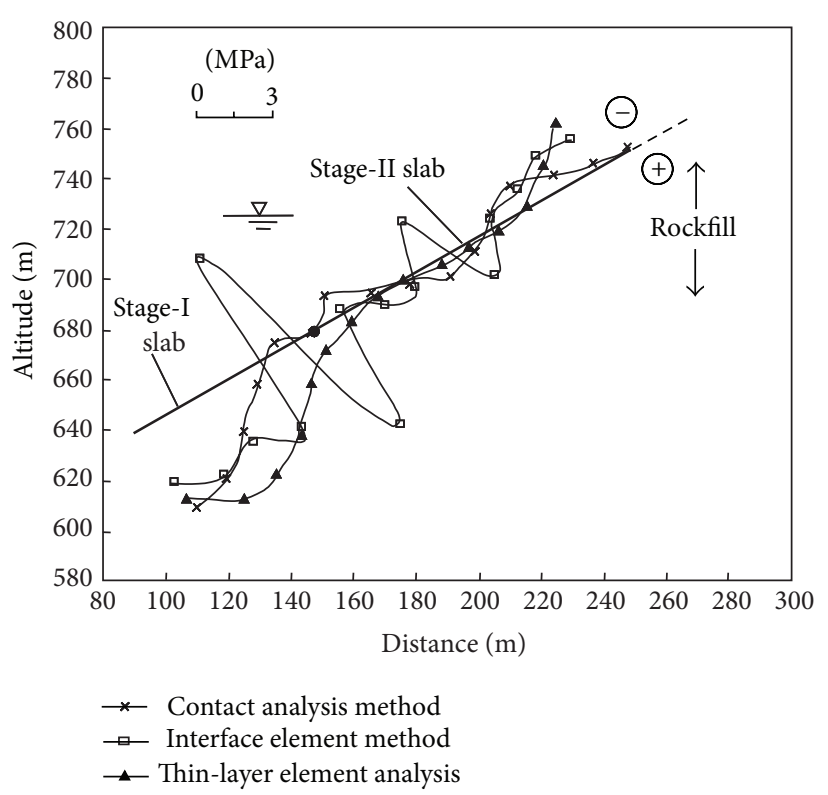

(a) Shear stress

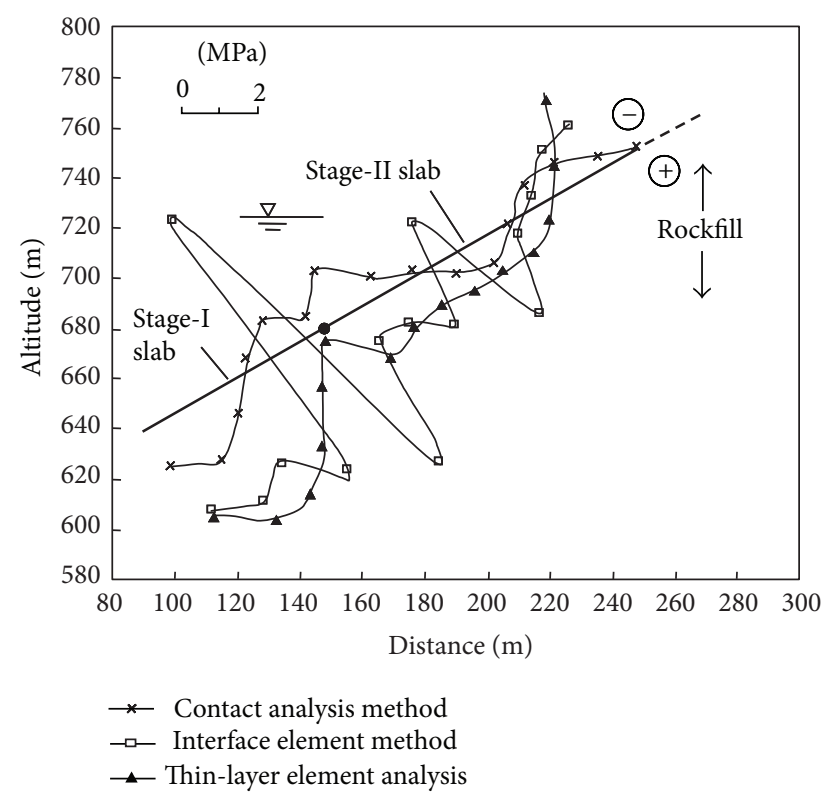

(b) Normal stress

FIgURE 14: Comparison of stresses in the concrete face slab at completion of the dam body construction.

\section{Conclusions}

This study compared the interface treatments in the interface element, thin-layer element, and contact analysis methods, and their numerical performance in predicting deformation, slab separation, contact stress along the interface, and stresses in the concrete face slab in the Tianshengqiao-I concretefaced rockfill dam, through two-dimensional finite element analysis. Numerical results were also compared with the insitu observations available. Based on these comparisons, the following conclusions and understanding can be drawn.

First, the three numerical methods predicted almost the same settlement and similar horizontal displacement, and the predicted deformation was in good agreement with the in-situ observation data. This indicated that the Duncan EB model used can correctly describe the nonlinearity of this high concrete-faced rockfill dam.

Second, interface element method cannot correctly simulate the slab separation. The predicted normal stress along the interface, and stresses in the concrete face slab were oscillatory and not accurate enough for cracking assessment. The thin-layer element method could reasonably predict the normal stress along the interface in some circumstances. However, because solid elements were used, there were intrinsic difficulties in simulating slab separation, and this often led to inaccurate stress distribution in the concrete slab.

Third, the contact analysis method could physically and quantitatively simulate the slab separation at different construction stages of the Tianshenqiao-I high CFRD dam. The predicted opening width and depth were in reasonable agreement with the in-situ observations. The normal contact stress along the interface and the stresses in the concrete face slab were reasonable. Furthermore, because no elements were used along the interface, the contact analysis method allowed nonmatching nodes on both sides of the interface and could incorporate complex physical and geometrical properties. The stress distributions obtained could be used for the evaluation of potential cracking risk in CFRDs.

The previous discussion indicates that, for contact problems involving large separation or slipping, the contact analysis method (as the most physically realistic approach) is the best numerical method, while the interface element and thin-layer element methods (as simplified contact treatments) are not applicable. Although the performance of these two methods can be largely improved through using more sophisticated constitutive models, applying a tension cut-off criterion, or allowing node-to-node contact, their intrinsic limitations (e.g., contact description based on fixed node pairs) make it difficult for them to obtain satisfactory results for complex contact problems. However, the contact analysis method is a relatively new approach for engineering applications and further studies should be conducted to improve its computational efficiency and stability.

\section{Acknowledgments}

The authors are grateful to the HydroChina Kunming Engineering Corporation for providing the in-situ observation data. The authors would like to thank the National Basic Research Program of China no. 2010CB732103, the National Natural Science Foundation of China no. 51209118, and the State Key Laboratory of Hydroscience and Engineering no. 2012-KY-02 for financial support.

\section{References}

[1] J. B. Cook and J. L. Sherard, Eds., Concrete Face Rockfill DamsDesign, Construction and Performance, ASCE, New York, NY, USA, 1985. 
[2] R. E. Goodman, R. L. Taylor, and T. L. Brekke, "A model for the mechanics of jointed rock," Journal of the Soil Mechanics and Foundations Division, vol. 94, no. 3, pp. 637-659, 1968.

[3] G. N. Pande and K. G. Sharma, "On joint/interface elements and associated problems of numerical ill-conditioning," International Journal for Numerical and Analytical Methods in Geomechanics, vol. 3, no. 3, pp. 293-300, 1979.

[4] G. Beer, "An isoparametric joint/interface element for finite element analysis," International Journal for Numerical Methods in Engineering, vol. 21, no. 4, pp. 585-600, 1985.

[5] A. Gens, I. Carol, and E. E. Alonso, "An interface element formulation for the analysis of soil-reinforcement interaction," Computers and Geotechnics, vol. 7, no. 1-2, pp. 133-151, 1989.

[6] J. G. Wang, Y. Ichikawa, and C. F. Leung, "A constitutive model for rock interfaces and joints," International Journal of Rock Mechanics and Mining Sciences, vol. 40, no. 1, pp. 41-53, 2003.

[7] K. Sekiguchi, R. K. Rowe, and K. Y. Lo, “Time step selection for 6-noded non-linear joint element in elasto-viscoplasticity analyses," Computers and Geotechnics, vol. 10, no. 1, pp. 33-58, 1990.

[8] C. S. Desai, M. M. Zaman, J. G. Lightner, and H. J. Siriwardane, "Thin-layer element for interfaces and joints," International Journal for Numerical and Analytical Methods in Geomechanics, vol. 8, no. 1, pp. 19-43, 1984.

[9] M. M. Zaman, "Evaluation of thin-layer element and modeling of interface behavior in soil-structure interaction," in Proceedings of the 5th International Conference on Numerical Methods in Geomechanics, pp. 1797-1803, Nagoya, Japan, 1985.

[10] O. C. Zienkiewicz, B. Best, C. Dullage, and K. G. Stagg, "Analysis of nonlinear problems in rock mechanics with particular reference to jointed rock systems," in Proceedings of the 2nd Congress of the International Society for Rock Mechanics, pp. 814, Belgrade, Serbia, 1970.

[11] D. V. Griffiths, "Numerical modeling of interfaces using conventional finite elements," in Proceedings of the 5th International Conference on Numerical Methods in Geomechanics, pp. 837844, Nagoya, Japan, 1985.

[12] B. Zhang, J. G. Wang, and R. Shi, "Time-dependent deformation in high concrete-faced rockfill dam and separation between concrete face slab and cushion layer," Computers and Geotechnics, vol. 31, no. 7, pp. 559-573, 2004.

[13] N. Kikuchi and J. T. Oden, Contact Problems in Elasticity: A Study of Variational Inequalities and Finite Element Methods, vol. 8 of SIAM Studies in Applied Mathematics, SIAM, Philadelphia, Pa, USA, 1988.

[14] J. G. Wang and G. R. Liu, "A point interpolation meshless method based on radial basis functions," International Journal for Numerical Methods in Engineering, vol. 54, no. 11, pp. 1623$1648,2002$.

[15] J. G. Wang, T. Nogami, G. R. Dasari, and P. Z. Lin, "A weak coupling algorithm for seabed-wave interaction analysis," Computer Methods in Applied Mechanics and Engineering, vol. 193, no. 36-38, pp. 3935-3956, 2004.

[16] J. M. Duncan, P. Byrne, K. Wong, and P. Mabry, "Strength, stress-strain and bulk modulus parameters for finite element analysis of stresses and movements in soil masses," Tech. Rep. UCB/GT/80-01, University of California, Berkeley, Calif, USA, 1980.

[17] K. C. Park, C. A. Felippa, and G. Rebel, "A simple algorithm for localized construction of non-matching structural interfaces," International Journal for Numerical Methods in Engineering, vol. 53, no. 9, pp. 2117-2142, 2002.
[18] J.-H. Heegaard and A. Curnier, "An augmented Lagrangian method for discrete large-slip contact problems," International Journal for Numerical Methods in Engineering, vol. 36, no. 4, pp. 569-593, 1993.

[19] O. C. Zienkiewicz and R. L. Taylor, The Finite Element Method: Volume 1: The Basis, Butterworth-Heinemann, Oxford, UK, 5th edition, 2000.

[20] A. Corigliano and U. Perego, "Generalized midpoint finite element dynamic analysis of elastoplastic systems," International Journal for Numerical Methods in Engineering, vol. 36, no. 3, pp. 361-383, 1993.

[21] HydroChina Kunming Engineering Corporation, Tianshengqiao-I Hydropower Project Engineering Safety Assessment: Analysis of Monitoring Data, HydroChina Kunming Engineering Corporation, Kunming, China, 2000.

[22] J. C. J. Schellekens and R. de Borst, "On the numerical integrations of interface elements," International Journal for Numerical Methods in Engineering, vol. 36, no. 1, pp. 43-66, 1993. 


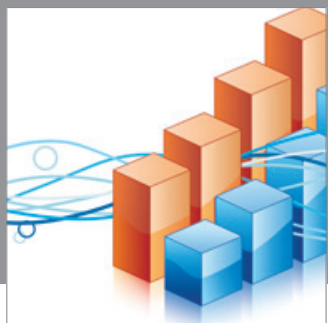

Advances in

Operations Research

mansans

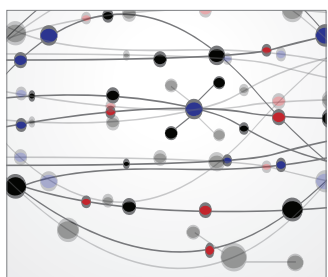

The Scientific World Journal
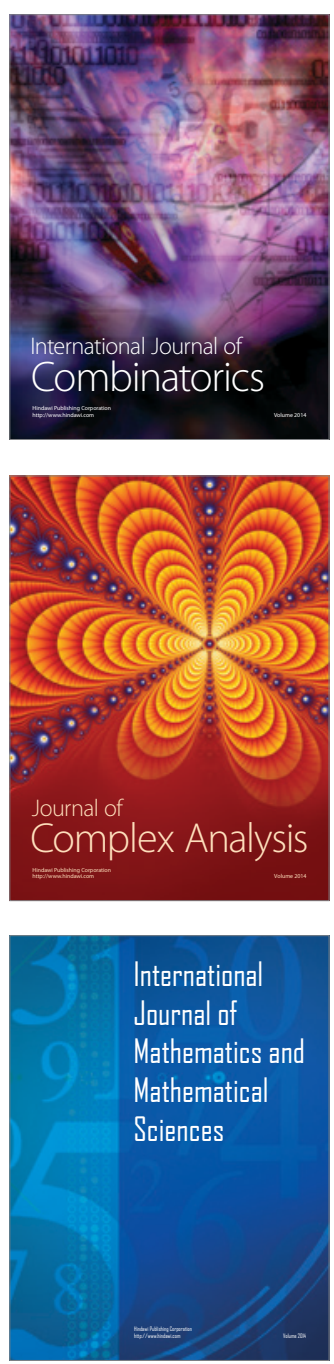
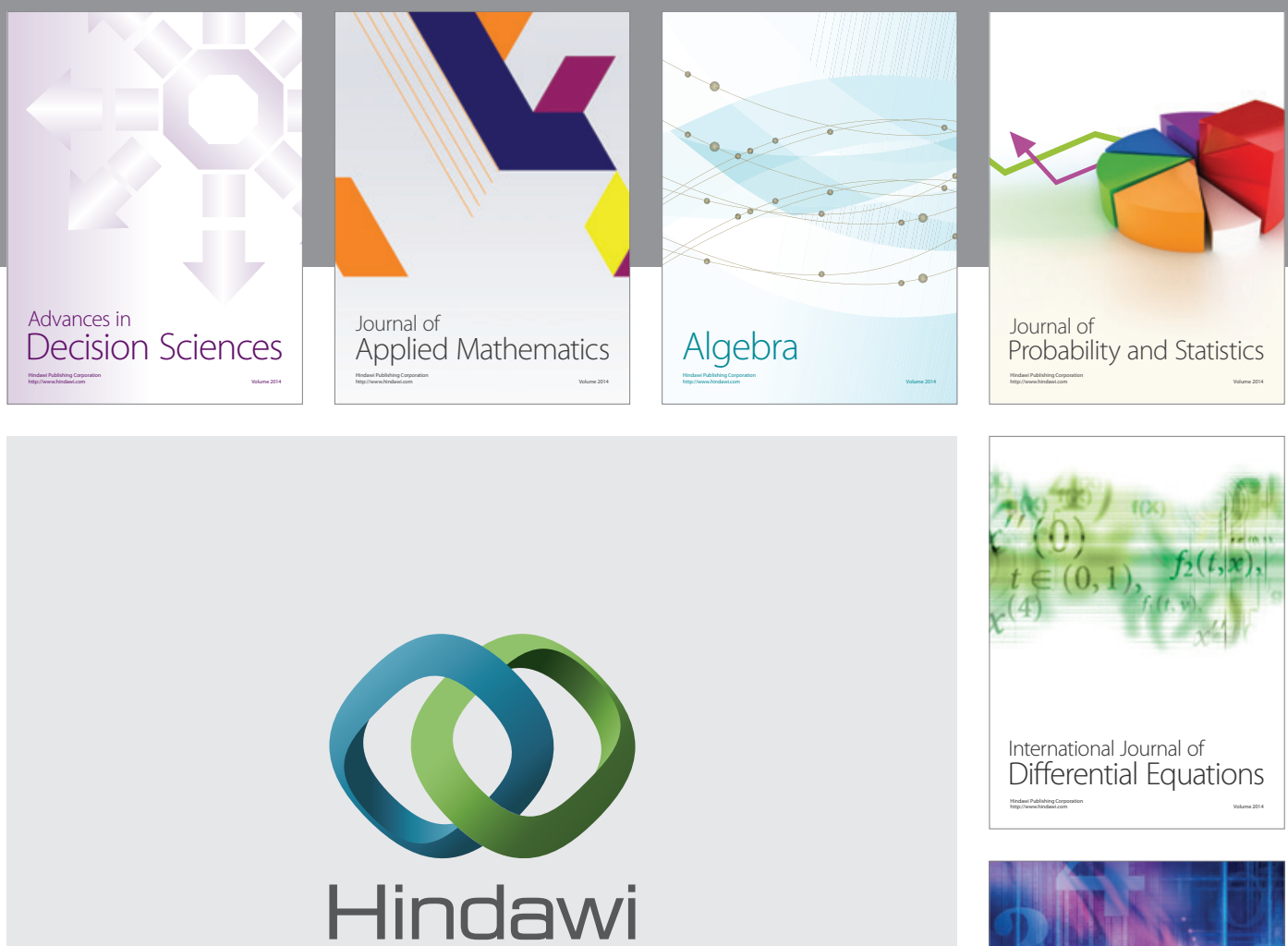

Submit your manuscripts at http://www.hindawi.com
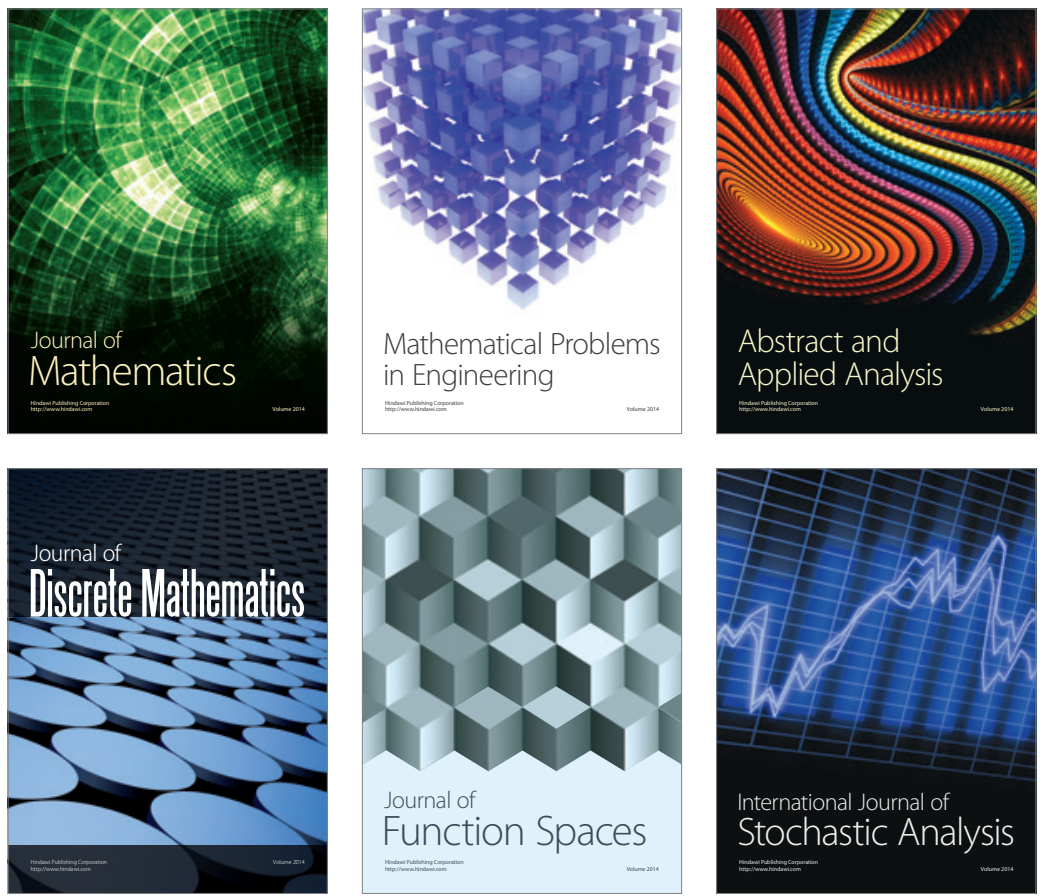

Journal of

Function Spaces

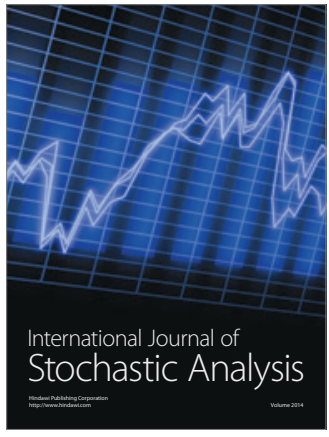

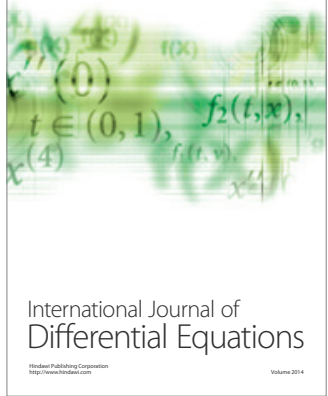
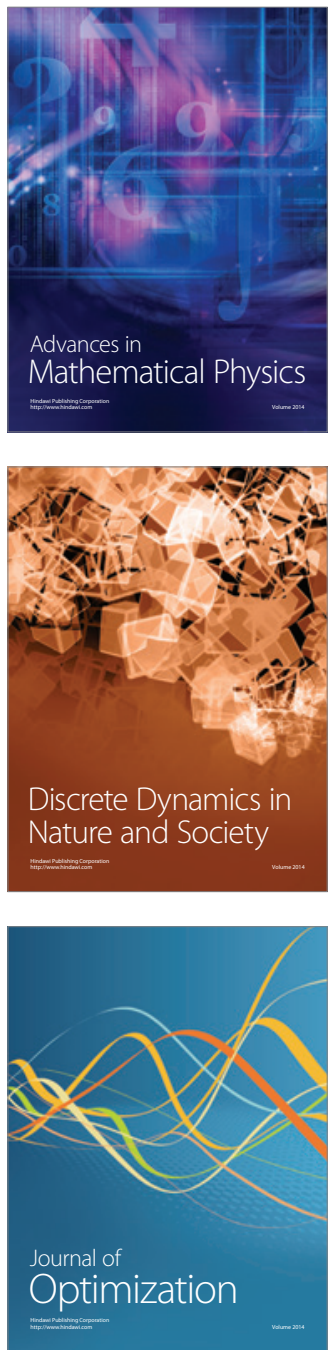